\title{
Biosynthesis of the Antibiotic Nisin and Other Basic Peptides by Streptococcus lactis Grown in Batch Gulture
}

\author{
By A. HURST* \\ Unilever Research Laboratory, Colworth House, Sharnbrook, Bedford
}

(Received 11 May 1966)

\begin{abstract}
SUMMARY
Streptococcus lactis was grown in batch culture in a complex organic medium. Growth of the culture was followed by estimating the extinction, the dry weight, protein, DNA and RNA of the organism; basic peptides were estimated by electrophoresis and nisin by bio-assay. By the end of the lag phase of growth when active DNA and RNA synthesis were already proceeding, the nisin which had been introduced with the inoculum could not be recovered, although the cocci contained other basic peptides. Rapid nisin synthesis started after an increase of about $50 \%$ in the dry weight of the cocci had taken place. Initially, high molecular weight nisin was made, the concentration of which decreased as the incubation proceeded. This was followed by the production of lower molecular weight nisin which could be recovered $24 \mathrm{hr}$ after the end of the incubation. Inocula of organisms derived at intervals from the parent culture were tested in secondary cultures for length of lag of growth by re-inoculation into fresh medium of the same composition. During the lag phase of growth of the parent culture, the length of lag of growth of the secondary cultures fell to about half the original time. The shortest lag of the secondary cultures coincided with commencement of logarithmic growth of the parent culture and with the disappearance of cellular nisin from the parent culture. The length of the lag of the secondary cultures returned to their original value as the parent culture reached stationary phase and coincided with maximum nisin concentration in the parent culture. It is suggested that the length of lag of growth is related to the presence of basic peptides.
\end{abstract}

\section{INTRODUCTION}

A variety of micro-organisms produce antibiotic peptides, but the function of these substances to the organism producing them is unknown. Katz, Wise \& Weissbach (1965) speculated that the synthesis of actinomycin might represent terminal growth processes. Bernlohr \& Novelli (1963) were able to feed doubly labelled bacitracin to cultures of Bacillus licheniformis and recover the antibiotic in an apparently unchanged condition from the spores; they concluded that it might form a subunit of the spore coat. On the other hand, Brenner, Gray \& Paulus (1964) were unable to recover polymyxin from the spore coat of $B$. polymixa and concluded that polymyxin, if present, was less than $0 \cdot 2 \%$ of the dry weight of the spore. Woodruff (1966) believed that antibiotics are waste products of the cell formed at a time when an essential metabolite becomes limiting.

\footnotetext{
* Formerly A. Hirsch.
} 
Halvorson (1965) suggested that polypeptide antibiotics may play a part in the differentiation of the vegetative bacterium by repressing the vegetative cell genome. This suggestion is supported by the results of Spizizen (1965) who found that asporogenous mutants of bacilli also failed to produce an 'antibacterial factor'. Szabo, Vitalis \& Bekesi (1966) obtained a polypeptide from a conidia forming Streptomyces which restored the conidial forming ability of a mutant which ceased to form them; the polypeptide appeared to stabilize messenger RNA. Moore \& Shockman (1966) obtained a basic polypeptide from Streptococcus faecalis which inhibited protein synthesis in a cell-free system prepared from the same organism; this inhibitor appeared to be associated with RNA. Hurst \& Taylor (1965) were able to isolate, in three out of seventeen attempts, basic peptides from Escherichia coli which inhibited the growth of the organism from which these substances were isolated.

Washed suspensions of Streptococcus lactis synthesized nisin by a mechanism which was similar to that of protein synthesis, in that it was sensitive to inhibition by chloramphenicol and puromycin but differed by being more sensitive to these antibiotics and synthesis was always preceded by a delay (Hurst, 1966). Growing cultures also show a delay of synthesis of nisin since this did not start till the logarithmic phase of growth (Hirsch, 1951). In this respect nisin synthesis resembles that of other polypeptide antibiotics (for review see Abraham, Newton \& Warren, 1965). This differential synthesis, if confirmed, could suggest that the basic peptides and nisin had a possible function in the life-cycle of the organism. The present paper describes experiments to examine this and relates nisin biosynthesis to other biochemical events which occur during the growth of the organism.

\section{METHODS}

Organisms, media and culture conditions were described before (Hurst, 1966) For cultivation experiments the nisin producing Streptococcus lactis was subcultured twice at $24 \mathrm{hr}$ intervals and then used as inoculum for batch culture. Immediately before inoculation the culture was diluted with an equal volume of medium 22 prewarmed to $30^{\circ}$ and incubated for $1 \mathrm{hr}$ at $30^{\circ}$; the volume was adjusted to give a $5 \%(\mathrm{v} / \mathrm{v})$ inoculum. Incubations were usually done in $20 \mathrm{l}$. volumes and no attempts was made to stir, or to control the $\mathrm{pH}$ value or oxygen tension.

\section{Preparation of samples and estimations}

Length of lag of growth. Samples of the culture were taken at intervals during incubations to estimate the length of the lag time of the culture at different stages of the growth cycle. The samples were cooled in crushed ice and the cocci centrifuged off in the cold. They were taken up in chilled distilled water and the extinction $(E)$ adjusted to correspond to $6-8 \mathrm{mg}$. dry wt. organism $/ \mathrm{ml}$. This was then diluted 1/100 in medium 22 at $30^{\circ}$ and incubated in a $30^{\circ}$ water bath. The moment when the cold culture was diluted with the warm medium was taken as time zero. At intervals the extinction of this secondary culture was determined and the results were plotted as a series of curves of extinction against time. A tangent was drawn through the lag-phase points of the curves and another tangent through the logarithmic phase points; the intersect of the tangents was read off on the time scale and was the estimated length of lag in minutes (Monod, 1949; Meynell \& Meynell, 1965). 
Extinctions were measured on an S.P. 600 spectrophotometer at $600 \mathrm{~m} \mu$ in $1 \mathrm{~cm}$. cuvettes (Cambridge Instrument Co.).

Nucleic acids and protein. Reaction was stopped by diluting samples with an equal volume of cold N-perchloric acid (PCA). After two washes with cold $0.5 \mathrm{~N}-\mathrm{PCA}$ the nucleic acids were extracted 3 times with $0.5 \mathrm{~N}-\mathrm{PCA}$ at $70^{\circ}$ for $30 \mathrm{~min}$. The residue was dissolved in $2 \mathrm{~N}-\mathrm{NaOH}$ and was used for estimating protein by the method of Lowry, Rosebrough, Farr \& Randall (1951). The supernatant fluid was used to estimate DNA by the diphenylamine method (Burton, 1956) and RNA by the orcinol method (Mejbaum, 1939).

Nisin (free and bound = total nisin) was estimated by the modified method of Berridge \& Barrett as previously described (Hurst, 1966). For estimating nisin bound to the organisms (cellular nisin) the reaction was stopped by chilling, the organisms centrifuged down in the cold and the supernatant fluid replaced by an equal volume of $0.05 \mathrm{~N}-\mathrm{HCl}$ in which the cocci were resuspended. The nisin was then extracted by placing the tubes in a boiling water bath for $5 \mathrm{~min}$. and the extracts assayed as before against Streptococcus cremoris (strain 1P5).

Preparation of basic peptides and nisin. Treatment as described above with hot $0.05 \mathrm{~N}-\mathrm{HCl}$ extracted nucleic acids, basic peptides and nisin. The nucleic acids were not examined and were lost in the purification steps. Nisin and basic peptides which might have been in solution also were not examined. The method used aimed to estimate the qualitative and semi-quantitative changes which occurred in the cells during a growth cycle and was as follows. During the early phases of growth when the concentration of organisms was only $100-200 \mu \mathrm{g}$. dry wt./ml., 3-4 l. of culture medium were chilled by mixing with crushed distilled water ice and the cocci centrifuged down in the cold. As growth proceeded and the concentration of cocci increased, $1 \mathrm{l}$. samples were sufficient; these could be chilled quickly by immersion into crushed ice. In this way the quantity of cocci for each preparation was kept approximately constant and enabled semi-quantitative comparison to be made of the final preparations, irrespective of the original concentration of cocci in the culture. The cocci so obtained were washed once with cold $0 \cdot 1 \mathrm{M}$-phosphate buffer $(\mathrm{pH} \mathrm{r})$ and then $1 \mathrm{~g}$. wet wt. cocci were taken up in $10 \mathrm{ml} .0 .05 \mathrm{~N}-\mathrm{HCl}$, placed in a boiling water bath for $5 \mathrm{~min}$., cooled, centrifuged and the deposit discarded. The basic peptides were concentrated into $n$-propanol by the method of Cheeseman \& Berridge (1957); each $100 \mathrm{ml}$. of solution in 0.05 N-HCl was shaken up with $15 \mathrm{ml}$. $n$-propanol, followed by $21 \mathrm{~g}$. $\mathrm{NaCl}$, shaken and then left to stand, This operation was not repeated. The propanol layer and the interface beneath it were pipetted off and evaporated in a rotary evaporator to near dryness or were freeze dried. The dry material was then made up to $15 \mathrm{ml}$. with $5 \%(\mathrm{v} / \mathrm{v})$ acetic acid and desalted through a $1 \times 15 \mathrm{~cm}$. column of Amberlite resin CG 50 (British Drug Houses Ltd., Poole, Dorset) finished in the $\mathbf{H}^{+}$form (Dixon, 1959). The column was washed with $5 \%(\mathrm{v} / \mathrm{v})$ acetic acid and the basic peptides eluted with $\mathbf{5 0} \%$ acetic acid. Figure 1 shows the elution histogram of nisin. The active fractions were combined and freezedried.

Electrophoresis. The freeze dried powders were made up as $1 \%(\mathrm{w} / \mathrm{v})$ solutions in $0.05 \mathrm{~N}-\mathrm{HCl}$. The solutions were run in polyacrilamide gels prepared by the method of Tombs $(1965) ; 20 \%(\mathrm{w} / \mathrm{v})$ gels were made up in distilled water and after setting were equilibrated for 1 day with a $\mathrm{pH} 2$ 'buffer' made up of $11.5 \mathrm{ml}$. formic acid, 
$1500 \mathrm{ml}$. glycerol and distilled water to $5 \mathrm{l}$. Purified nisin (kindly provided by $\mathrm{Dr}$ J. Tramer, United Dairies Central Laboratories, London) and polymyxin (Burroughs Wellcome Ltd., London) in a mixture each at $1 \%(\mathrm{w} / \mathrm{v})$ in $0.05 \mathrm{~N}-\mathrm{HCl}$ were used as markers. The electrophoresis was run in the same buffer at $12.5 \mathrm{~V} / \mathrm{cm}$. and $0.5 \mathrm{~mA}$ for 4-6 hr. The gels were stained for $5 \mathrm{~min}$. with naphthalene black and decolorized by washing with distilled water.

Bands of growth inhibitory substances were identified by placing the gels on agar plates seeded with Streptococcus cremoris. To prevent inhibition due to acidity the gels were first neutralized by washing in the cold with $0.05 \mathrm{M}$-tris buffer $(\mathrm{pH} 8)$. The gel was then dried with cellulose tissue and placed on the surface of a yeast glucose agar plate inoculated $1 \%(\mathrm{v} / \mathrm{v})$ of the culture nisin bioassay test-organism. Alternatively, two gels were run simultaneously; one was then stained and the other was neutralized. The stained gel was used to guide the slicing of the unstained but

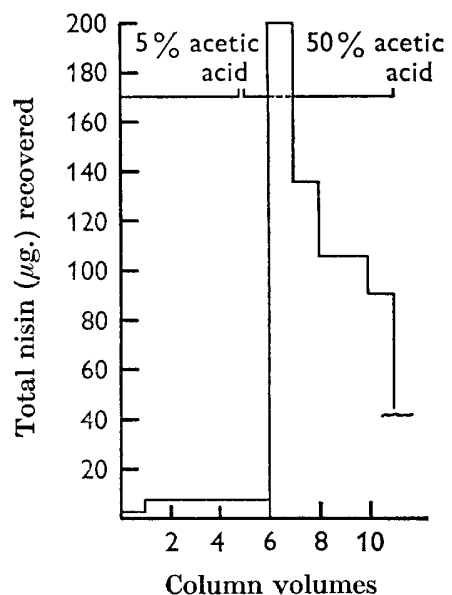

Fig. 1

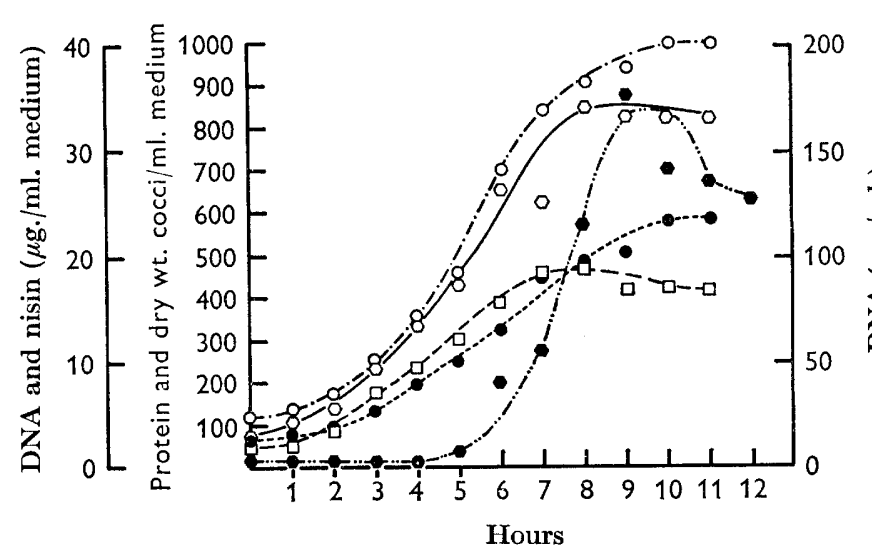

Fig. 2

Fig. 1. Elution histogram of nisin from Amberlite Resin CG50.

Fig. 2. Biosynthetic activities of Streptococcus lactis growing in batch culture. Dry weight, $\mathrm{O}_{-}-$; DNA, $\mathrm{O}-$; Nisin, - -..-; Protein, - -- - RNA,

neutralized gel; the slices of gel were then placed on the seeded agar plates.

After contact for $1 \mathrm{hr}$ the gel was removed and the plate incubated overnight at $30^{\circ}$; because of the high concentrations needed for electrophoresis, contact for longer than $1 \mathrm{hr}$ could completely clear the agar plate; contact for less than $1 \mathrm{hr}$ was not tried.

\section{RESULTS}

\section{Characteristics of the growth of Streptococcus lactis}

The composite data in Fig. 2 are based on four separate experiments and show the sequence of changes taking place during batch culture. Comparison between experiments showed that the length of the lag varied, the slope of the growth curve varied and the rate at which the nisin was formed during the experiment and subsequently disappeared also varied. However, these differences were considered to be 
inherent in experiments done with different inocula, in different batches of media and were not investigated further.

Figure 2 shows that during the first $2 \mathrm{hr}$ the dry weight and protein of the organism increased less than DNA and RNA. The DNA and RNA synthesis attain maximum rate before protein synthesis and dry weight increase. The small amount of nisin introduced with the inoculum decreased during the lag phase. Total nisin was

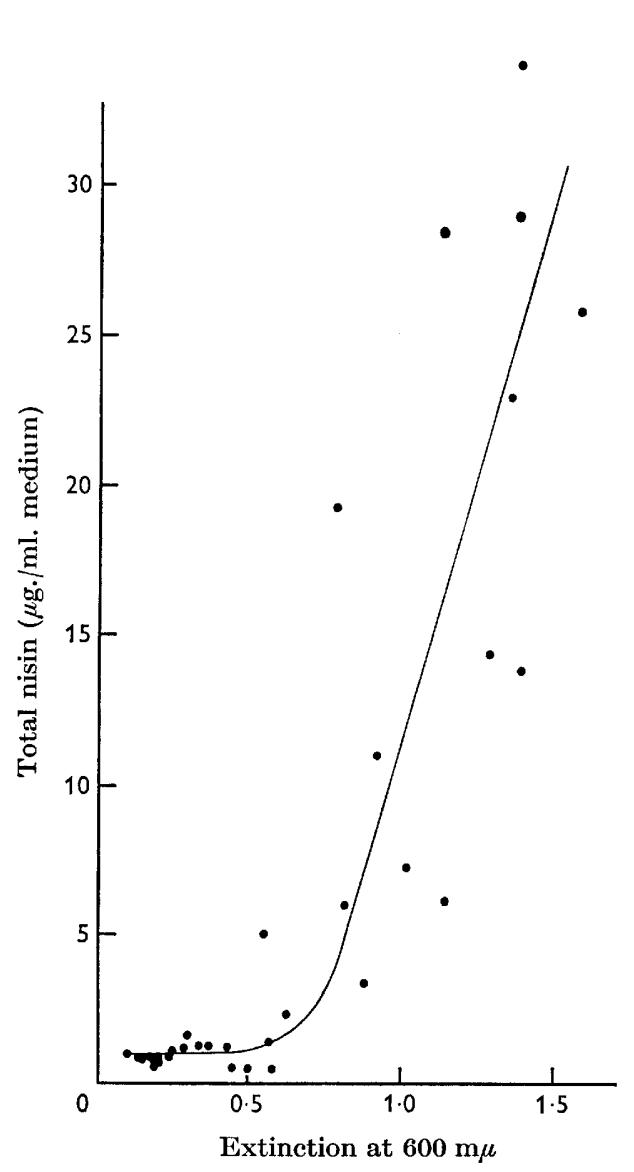

Fig. 3

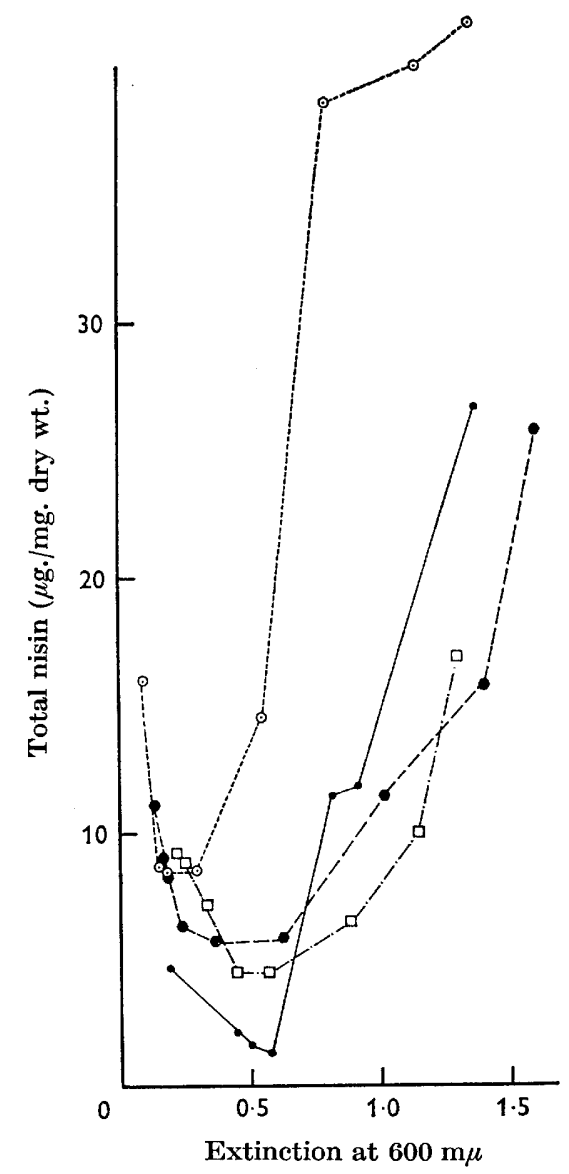

Fig. 4

Fig. 3. Growth of Streptococcus lactis and differential synthesis of nisin.

Fig. 4. Growth of Streptococcus lactis and differential synthesis of nisin in four different fermentation experiments. Expt. 1, $\odot,---$; Expt. 2,

Expt. 4, $\square-$ - - -

maximal at $9 \mathrm{hr}$ after which it decreased. From Fig. 2 it can be seen that nisin and protein synthesis occurred at different rates, Fig. 3 is a differential plot made according to Monod, Pappenheimer \& Cohen-Bazier (1952); the extinction was the measure usually used and has been used in Fig. 3, which presents all the data obtained in four separate experiments over 5 months. Figure 3 shows that nisin synthesis did not occur during the early stage of the growth when the extinction 
was low. Its rate increased sharply after considerable growth had already taken place. Figure 4 is based on the same data as Fig. 3 but the data plotted are $\mu$ g. total nisin/mg. dry wt. against the extinction. In Fig. 4 the results of the four experiments which were made on separate occasions can no longer be superimposed and are shown separately. Not only is the differential rate of nisin synthesis evident but a new phenomenon is seen, namely that the nisin introduced with the inoculum was so modified that it was not detected by the bio-assay.

The data of Figs. 2-4 referred to total nisin; Fig. 5 is the record of an experiment especially designed to follow cellular nisin during the early parts of the incubation. It confirms the suggestion of Fig. 4 that cellular nisin was first destroyed before active synthesis began.

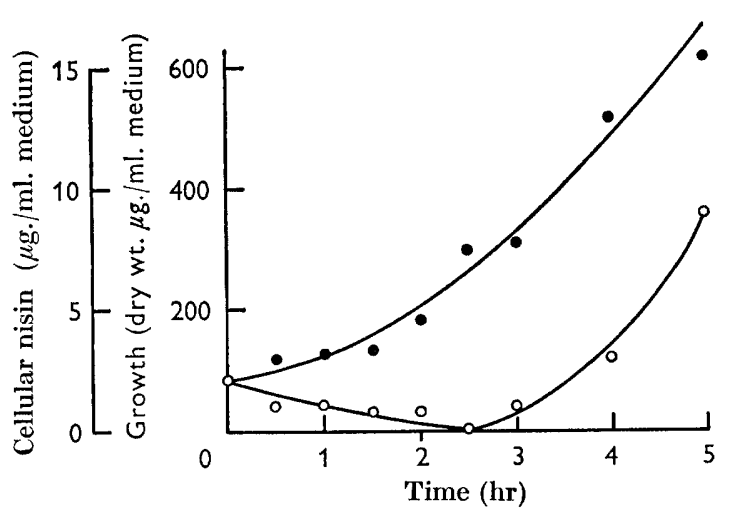

Fig. 5

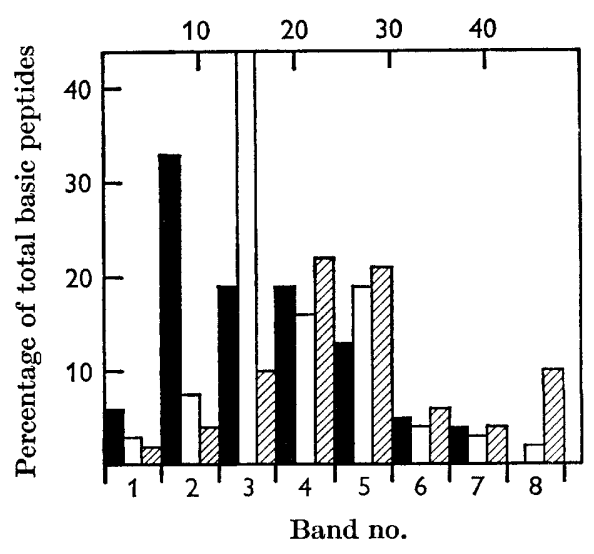

Fig. 6

Fig. 5. Initiation of growth of Streptococci lactis and synthesis and disappearance of cellular nisin. Growth, ; cellular nisin,

Fig. 6. Percentage distribution of different basic peptides in cultures of Streptococcus lactis, 3,7 and $15 \mathrm{hr}$ old. Culture age $3 \mathrm{hr}, \mathbf{D}$; culture age $7 \mathrm{hr}, \square$; culture age $15 \mathrm{hr}, \square$. Band seven corresponds to high mol.wt. nisin (slow nisin). Band eight corresponds to nisin.

Electrophoresis of the basic peptides formed at different stages of growth. The markers, nisin and polymyxin were well separated, the lower molecular weight polymyxin being about $25 \mathrm{~mm}$. in front of nisin. Frequently, the purified nisin was split into two components, a small amount of slower moving material ('slow nisin') and a main component which was faster moving but was, nevertheless, well behind polymyxin.

Preparations made from 3,7 and $15 \mathrm{hr}$ cultures revealed up to eight bands of basic peptides. Band 1, the highest molecular weight material remained near the origin; band 7 corresponded to 'slow nisin' and band 8 to the faster moving main nisin component. Bands 2-6 occupied an intermediate position. Band 8 (main nisin component) was absent in the preparation made from the $3 \mathrm{hr}$ culture. Preparations made from $7 \mathrm{hr}$ cultures contained a considerable amount of slow-moving bands 2-6 material, 'slow nisin' (band 7) and traces of nisin (band 8). Preparations made from $15 \mathrm{hr}$ culture contained more of band 8 than band 7 and the intensity of bands 2-6 diminished. 
These results can be expressed quantitatively as shown in Fig. 6. Photographs of gels were examined in an integrating densitometer ('Chromoscan', Joyce Loebl and Co., Newcastle on Tyne); each area of each preparation was taken as $100 \%$ and the eight bands present in each preparation were expressed as a percentage of the total area of that preparation.

Impressions of gels on seeded agar plates showed that only the faster bands were inhibitory (bands 7 and 8). Bands 2-6 were not inhibitory. Occasionally band 1 (origin) was also inhibitory. Since the front of the $3 \mathrm{hr}$. preparation and that of the $15 \mathrm{hr}$ preparation did not correspond, this was additional evidence that at least two inhibitors were present in the $15 \mathrm{hr}$ preparation, but only traces of one in the $3 \mathrm{hr}$. preparation. Both bands of the marker nisin appeared to be inhibitory. Polymyxin did not inhibit the test-organism Streptococcus cremoris.

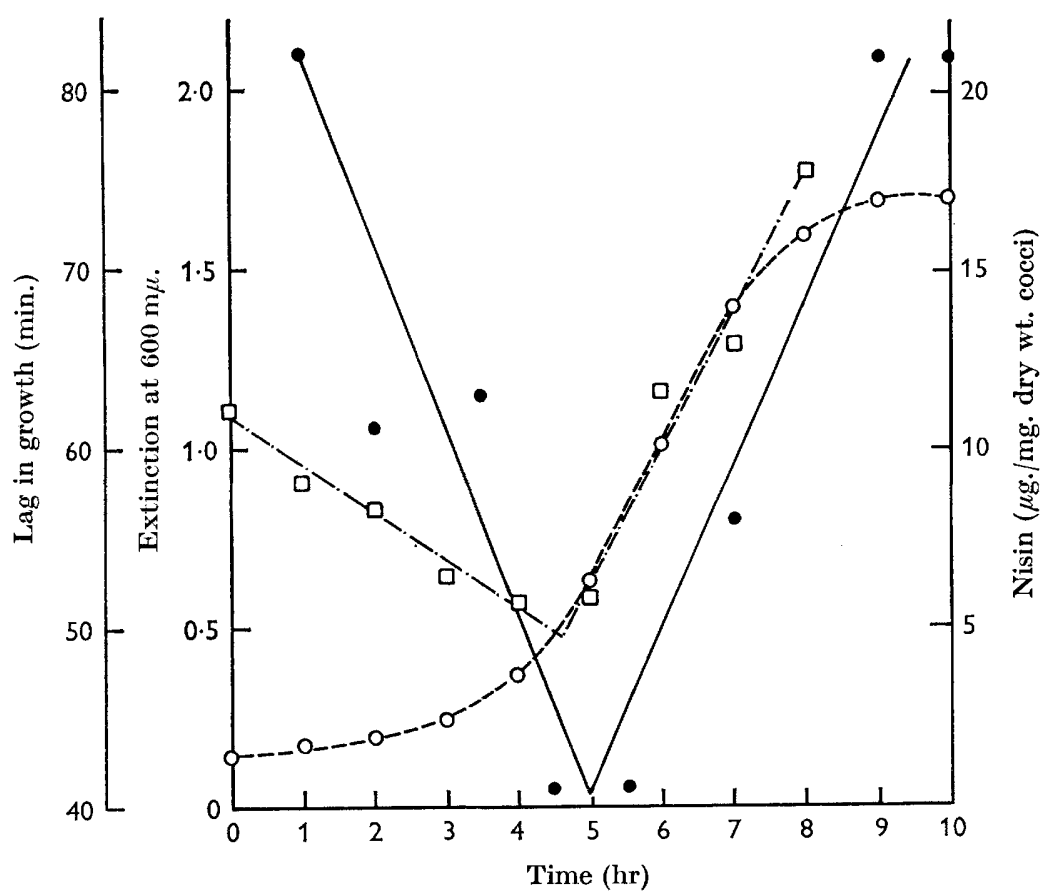

Fig. 7. Growth, synthesis of total nisin and length of lag of a culture of Streptococcus lactis. Minutes of lag of growth, - - ; extinction $\mathrm{O}-\longrightarrow$; total nisin,

\section{Length of lag phase of growth}

Inocula made from the culture at different stages of the growth cycle showed that the lag decreased and then increased. The results of a typical experiment are shown in Fig. 7. Samples taken during the early part of the incubation gave a lag of $82 \mathrm{~min}$.; this decreased to $41 \mathrm{~min}$. at the point when the culture entered the logarithmic growth phase; the lag of growth rose again to $82 \mathrm{~min}$, with samples from the culture entering the stationary phase. Figure 7 also shows that the concentration of nisin ( $\mu \mathrm{g} . / \mathrm{mg}$. dry wt. cocci) followed a similar variation with time. This observation was repeated in three independent experiments. 


\section{Description of the biochemical events which occur during growth}

DNA and RNA synthesis began during the lag period of growth (Fig. 2). At the same time the nisin introduced with the inoculum gradually diminished and at $2 \frac{1}{2} \mathrm{hr}$ no nisin was recovered from the cocci (Fig. 5). Electrophoresis showed that $\mathbf{3} \mathrm{hr}$ cocci had little or no nisin corresponding to that which was the main component of $15 \mathrm{hr}$ cocci, although they contained considerable amounts of other basic peptides. When the cocci were harvested at intervals and used as inocula to initiate new growth the lag period of growth first decreased and then increased while the parent culture was in the late logarithmic phase of growth. The minimum and maximum lag periods of growth and the mimimum and maximum nisin concentrations almost coincided (Fig. 7).

During the logarithmic phase of growth, RNA, DNA and protein increased at about the same relative rates. Rapid nisin synthesis started after the concentration of organisms as dry wt, had increased by $50 \%$ of the total attained in $12 \mathrm{hr}$ (Figs. 2, 3). Electrophoresis showed that $7 \mathrm{hr}$ cocci had all the basic peptide components of $15 \mathrm{hr}$ cocci but in different proportions. The nisin had two components; the slower moving band corresponded to the main nisin component of $7 \mathrm{hr}$ cocci which had little of the faster moving component. This situation was reversed in the preparations made from $15 \mathrm{hr}$ cocci (Fig. 6.)

The stationary phase of growth started by the halting of the synthesis of DNA, RNA, protein and nisin (Fig. 2). The electrophoretic pattern of preparations made from $24 \mathrm{hr}$ cocci was similar to that obtained from $15 \mathrm{hr}$ cocci.

\section{DISCUSSION}

It was suggested (Hurst, 1966) that nisin synthesis resembles protein synthesis. Cheeseman \& Berridge (1957) suggested that the molecular weight of nisin was 7000; this puts it in the class of small proteins. Bodansky \& Perlman (1964) suggested that the molecular weight of nisin was more likely to be one-third of the figure given by Cheeseman \& Berridge. However, the clear separation of nisin from polymyxin (which has molecular weight of 1250) and its lack of non-specific diffusion in polyacrilamide gels suggest that the original estimate of Cheeseman \& Berridge is more likely to be correct. The synthesis of nisin is clearly differentiated from that of other intracellular proteins; during early growth nisin synthesis does not take place, and this delay in synthesis is similar to that previously observed with washed organisms (Hurst, 1966). Figure 3 also resembles previously published figures for the induced synthesis of $\beta$-galactosidase by Escherichia coli (Monod et al. 1953, Nakada \& Magasanik, 1964; Moses \& Calvin, 1965). Streptococcus lactis also appears to have an inducible $\beta$-galactosidase system (Citti, Sandine \& Elliker, 1965). Perhaps the delay in nisin synthesis can be explained by a similar inductive control.

It is not known how Streptococcus lactis inactivates the nisin it produces before growth commences. Many bacterial species are known which inactivate nisin (Alifax \& Chevallier, 1962) but it was not previously known that the organism which produces nisin also inactivates it at two distinct periods of its growth in batch culture. The first of these points occurs during the lag phase of growth and might be explained either by the presence of an inactivating system or by multiplication of cocci which 
do not have nisin or both. A nisin-inactivating system seems more likely because the total nisin, not only cellular nisin, declined. Secondly, nisin destruction is indicated by the peak (Fig. 2) which occurred just before the onset of stationary phase of growth and which was consistently observed in four separate experiments. It can be explained by the disappearance of the 'slow nisin' (band r) as the culture aged. This was replaced by the faster moving nisin which remained stable for at least $24 \mathrm{hr}$; the cause of the instability of the slow band is not known. At least four different nisins are known to exist (Berridge, Newton \& Abraham, 1952).

Sonneborn (1963) stated that cell differentiation is associated with division but can also occur in the absence of division as cells grow older. It is difficult to tell which of these processes occurs in a growing bacterial culture. Jacob \& Monod (1963) defined differentiation as follows: 'Two cells are differentiated with respect to each other if, while they harbour the same genome, the patterns of proteins which they synthesize is different.' This is the process which has been demonstrated to occur with respect to nisin and other basic peptides when Streptococcus lactis grows in a batch culture. It is tempting to think that each individual in the population is preparing first for active growth by the destruction of the nisin which it carries, and at the end of the growth is preparing for dormancy by producing nisin. It is a classic observation of bacteriology that the resistance of cells to unfavourable physical conditions, salt, heat, irradiation, germicides, etc., vary with the growth phase (Porter, 1946). It is possible that nisin acts as a suppressor of a part of the genome concerned with rapid multiplication and enables the cell to synthesize more resistant systems. This suggestion is similar to that made by Halvorson (1965) for the function of peptide antibiotics in sporeforming bacteria. The suggestion made earlier that nisin synthesis is under inductive control also fits the bacillus antibiotic peptides (Srinivasan 1966). Recently it has been suggested that the whole sporulation process is connected with catabolic repression (Schaeffer, Millet \& Aubert, 1965). It follows from these suggestions that growth rate and initiation of growth (length of lag) may be two distinct processes, as has been shown in this paper. It is not the first time that such results have been reported and indeed, about 30 years ago this was the currently accepted concept (for review see Porter, 1946). Chesney (quoted by Porter, 1946) working with type I Pneumococcus, used a lag technique very similar to that described in this paper and obtained similar results. He regarded the occurrence of lag as 'an expression of injury which the bacterium has sustained from its previous environment'. The toxic agent in this case was later thought to be hydrogen peroxide. Since most microbes do not accumulate $\mathrm{H}_{2} \mathrm{O}_{2}$, Chesney's explanation fell into disrepute. However, the suggestion put forward in this work is that the length of lag of growth might be controlled by the presence of basic peptides.

The excellent technical assistance of Mr J. G. Dring is gratefully acknowledged. I am also grateful to Dr M. P. Tombs for valuable help and advice about electrophoresis. 


\section{REFERENCES}

Abraham, E. P., Newton, G. G. F. \& Warren, S. C. (1965). Problems relating to the biosynthesis of peptide antibiotics. In Biogenesis of Antibiotic Substances. Ed. by Z. Vanek and Z. Hostalek, p. 169. London: Academic Press.

Alifax, M. \& Chevallier, M. (1962). Étude de la nisinase produite par Streptococcus thermophilus. J. dairy Res. 29, 233.

Berridge, N. J., Newton, G. G. F. \& Abraham, E. P. (1952). Purification and nature of the antibiotic nisin. Biochem. J. 52, 529.

Bernlohr, M. W. \& Novelli, G. M. (1963). Bacitracin biosynthesis and spore formation: The physiological role of an antibiotic. Archs Biochem. Biophys. 103, 94.

Brenner, M., Gray, E. \& Paulus, H. (1964). The relation of polymyxin B to the spore coat of Bacillus polymyxa. Biochim. biophys. Acta 90, 401.

Bodansky, M. \& Perlman, D. (1964). Are peptide antibiotics small proteins? Nature, Lond. 204, 840.

Burton, K, (1956). A study of the conditions and mechanism of the diphenylamine reaction for the colorimetric estimation of deoxyribonucleic acid. Biochem. J. 62, 315 .

Cheeseman, G. C. \& Berridge, N. J. (1957). An improved method of preparing nisin. Biochem. J. 65, 1957 .

Citti, J. E., Sandine, W. E. \& Elliker, P. M. (1965). $\beta$-galactosidase of Streptococcus lactis. J. Bact. 89, 937 .

Dixon, H. F. B. (1959). A method of desalting certain polypeptides. Biochim. biophys. Acta 34, 251.

Halvorson, H. O. (1965). Sequential expression of biochemical events during intracellular differentiation. Symp. Soc. gen. Microbiol. 15, 343.

Hirsch, A. (1951). Growth and nisin production of a strain of Streptococcus lactis. J. gen. Microbiol. 5, 208.

Hurst, A. (1966). Biosynthesis of the antibiotic nisin by whole cells of Streptococcus lactis. J. gen. Microbiol. 44, 209.

Hurst, A. \& Taylor, D. R. (1965). Growth inhibition of Escherichia coli by some basic peptides prepared from the same strain. Nature, Lond. 207, 438.

$\mathbf{J}_{\mathrm{ACOB}}$, F. \& MoNOD, J. (1963). Genetic repression, allosteric inhibition and cellular differentiation. In Cytodifferentiation and macromolecular synthesis. Ed. by M. Locke, p. 30. London: Academic Press.

Katz, E. Wise, M. \& Weissbacif, H. (1965). Actinomycin biosynthesis. Differential effect of chloramphenicol on protein and peptide antibiotic synthesis. J. biol. Chem. 240, 3071 .

Lowry, O. H., Rosebrough, H. J., FArr, A. L. \& Randall, M. J. (1951). Protein measurement with the Folin phenol reagent. J. biol. Chem. 193, 265.

Mrjbaum, W. (1939). Über die Bestimmung kleiner Pentosemengen insbesondere die merivaten der Adenylesaure. Hoppe-Seyler's Z. physiol. Chem. 258, 117.

Meynell, G. G. \& Meynell, E. (1965). Theory and Practice in Experimental Bacteriology. Cambridge University Press.

Monod, J. (1949). The growth of bacterial cultures. Rev. Microbiol. 3, 371.

Monod, J., Pappenhermer, A. M. Jun. \& Cohen-Bazire, G. (1952). La cinétique de la biosynthese de la $\beta$-galactosidase chez $E$. coli considerée comme fonction de la croissance. Biochim. biophys. Acta 9, 648.

Moore, L. D. \& Shockman, G. D. (1966). Accumulation of an inhibitor of protein synthesis after amino-acid deprival. Fed. Proc. 25, 582.

Moses, V. \& Calvin, M. (1965). Lifetime of bacterial messenger ribonucleic acid. J. Bact. 90, 1205.

Nakada, D. \& Magasanik, B. (1964). The roles of inducer and catabolite repressor in the synthesis of $\beta$-galactosidase by Escherichia coli. J. mol. Biol. 8, 105.

Ponter, G. (1946). Bacterial Chemistry and Physiology. London: Chapman and Hall.

Schafffer, P., Millet, J. \& Aubert, J. P. (1965). Catabolic repression of bacterial sporulation. Proc. natn. Acad. Sci., U.S.A. 54, 704. 
Sonnebonn, T. M. (1963). The differentiation of cells. In The Scientific Endeavour, p. 217. NewYork: Rockefeller Institute Press.

Spizizen, J. (1965). Analysis of asporogenic mutants in Bacillus subtilis by genetic transformation. In Spores III. Ed. by L. L. Campbell and H. O. Halvorson, p. 125. American Soc. Microbiol.

SRINivasan, V. M. (1966). Sporogen-an 'inducer' for bacterial cell differentiation. Nature, Lond. 209, 537.

Szabo, G., Vitalis, S. \& Bekesi, I. (1966). Endogenous factor in differentiation of Streptomyces griseus. J. gen. Microbiol. 44, v.

Tombs, M. P. (1965). The interpretation of gel electrophoresis. Anal. Biochem. 13, 121.

Woodruff, H. B. (1966). Physiology of antibiotic production: the role of the producing organism. Symp. Soc. gen. Microbiol. 16, 22. 